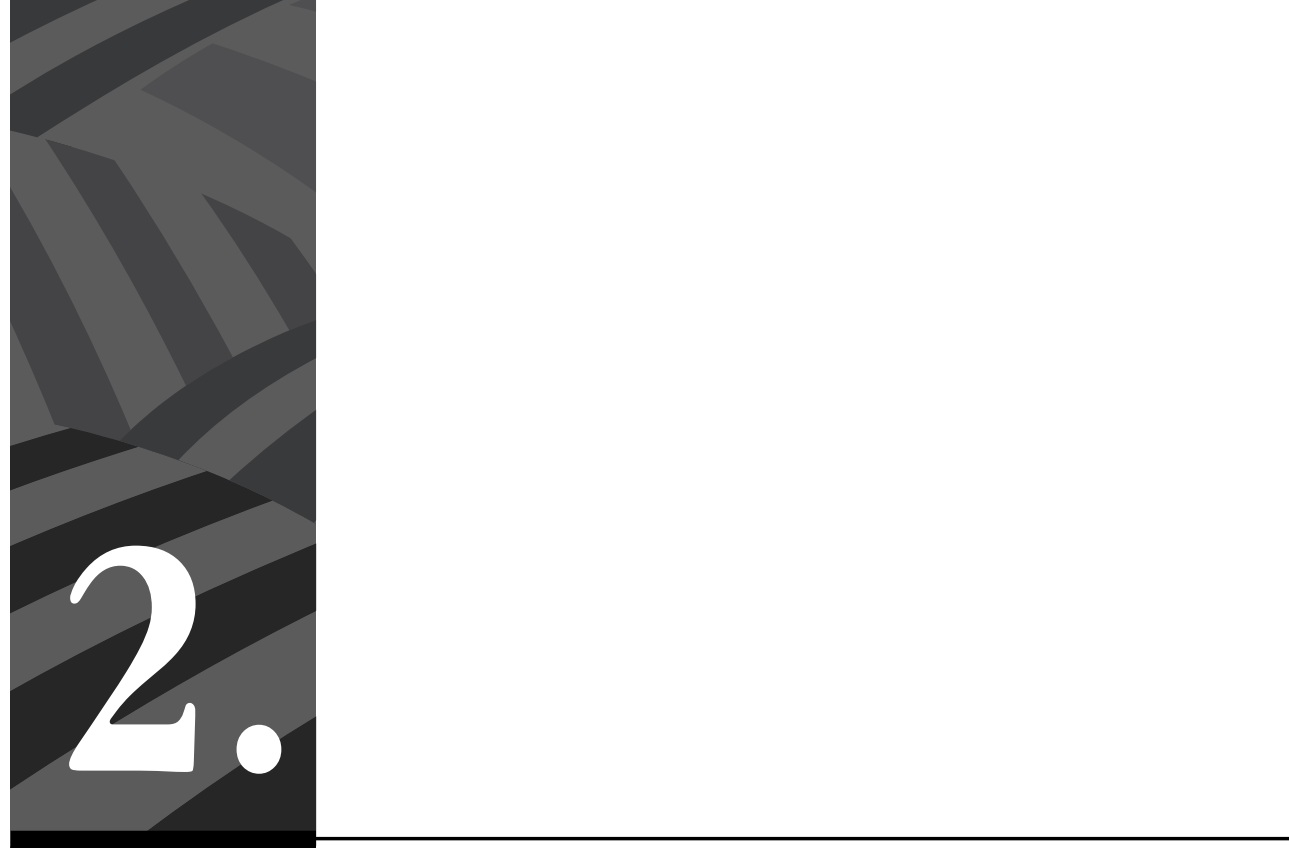

Violencias epistémicas

y acciones pedagógicas

de resistencia en el

Estado multicultural 


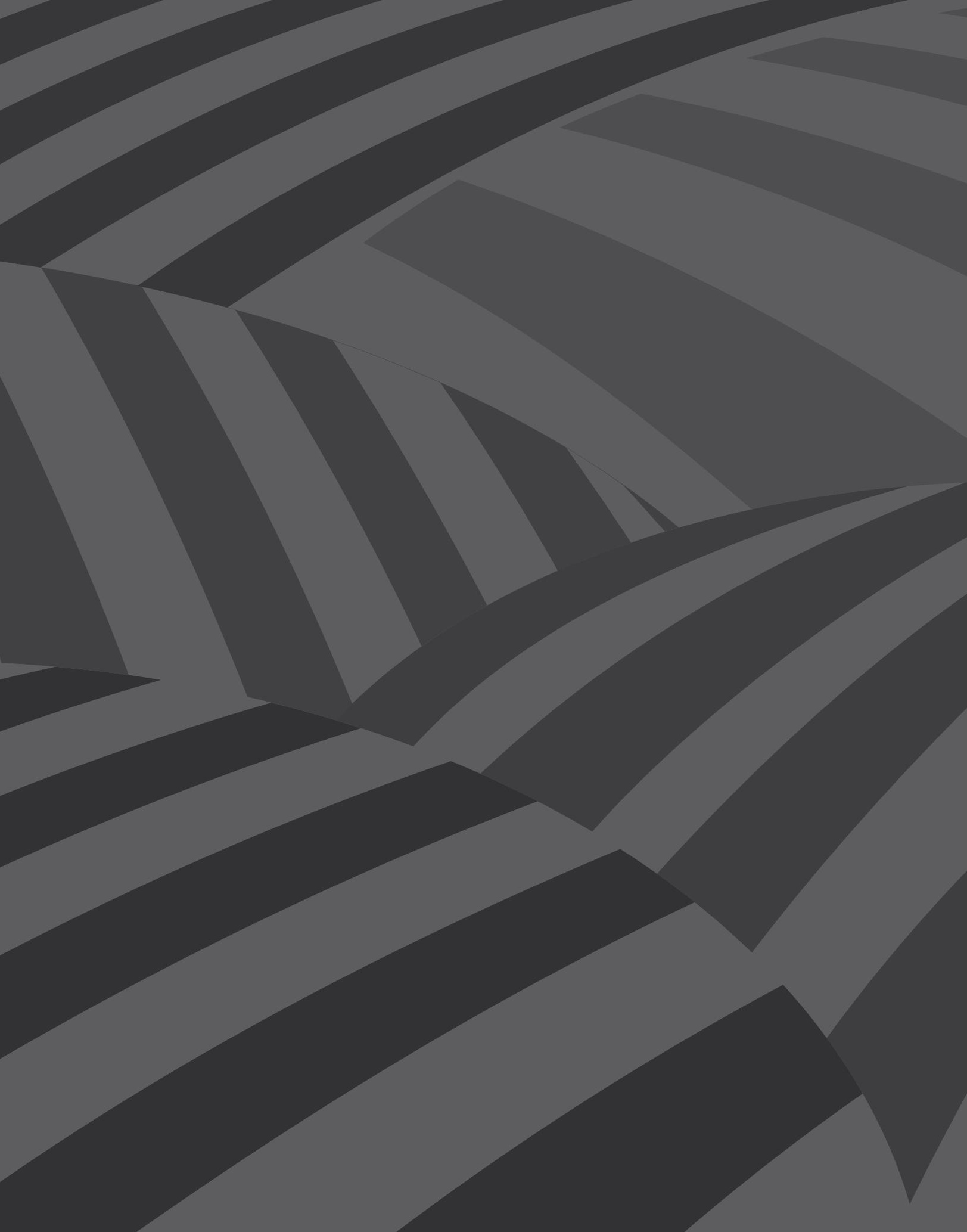




\title{
Violencias epistémicas y acciones pedagógicas de resistencia en el Estado multicultural
}

\author{
Por Leidy Laura Perneth Pareja*
}

Resumen: Las reflexiones que se presentan en este artículo surgen en el contexto del proyecto “Educación intercultural por la defensa de los derechos de los grupos étnicos", desarrollado por el Centro de Investigación y Educación Popular/Programa por la Paz (Cinep/PPP) en Cartagena, sur de La Guajira y Sierra Nevada de Santa Marta. A partir del trabajo con maestros y maestras wayúu, wiwas, afrodescendientes y mestizos, se argumenta que, en el marco de la relación entre los grupos étnicos y el Estado Multicultural, la etnoeducación y la educación propia -como política educativa- no logra transformar la posición epistémica desigual que ocupan los grupos étnicos en el sistema educativo colombiano. Aunque, en apariencia, para la política educativa son legítimos otros proyectos curriculares que operan a partir de las aspiraciones y planes de vida de los grupos étnicos, encontramos que los proyectos etnoeducativos no logran afectar la idea de un currículo nacional homogéneo, que se convierte en el único referente del sistema de evaluación, específicamente, de las pruebas que realizan los y las estudiantes a nivel nacional (Pruebas Saber). Este artículo muestra también que maestros y maestras -aunque no prescinden de ese currículo oficial- desarrollan prácticas curriculares en los bordes, donde se articulan acciones pedagógicas de resistencia en medio de tensiones con las políticas educativas nacionales.

Palabras clave: etnoeducación, educación propia, currículo oficial, violencia epistémica, evaluación, bordes, resistencia.

\section{Epistemic violence and pedagogical actions of resistance in the multicultural State}

Abstract: The reflections presented in this article were produced as part of the project "Educación intercultural por la defensa de los derechos de los grupos étnicos” developed by Centro de Investigación y Educacion Popular/Programa por la paz (Cinepp/PPP) in Cartagena, south of Guajira and Sierra Nevada in Santa Marta. Drawing from work with Wayuu, Wiwas, Afrodescendant, and

* Trabajadora social de la Universidad de Cartagena y Magíster en Estudios Culturales de la Universidad de los Andes. 
Mestizo teachers, it is argued that, in the framework of the relations between ethnic groups and the multicultural State, ethno-education and own-education -as educational policies- fail to transform the unequal epistemic position occupied by ethnic groups in the Colombian educational system. In the surface, these educational policies seem to legitimate other curricular projects that operate within ethnic groups' own life aspirations and plans. However, it was found that ethno-educational projects actually fail to challenge the concept of a homogeneous national curriculum, one that becomes the only reference of the educational assessment system through the national tests taken by students across the country (Pruebas Saber). This article further shows that teachers -despite not putting aside the official curriculum- develop curricular practices 'at the borders', where pedagogical actions of resistance are articulated in tension with national educational policies.

Keywords: ethno-education, own-education, official curriculum, epistemic violence, assessment, borders, resistance.

Cómo citar este artículo: Perneth Pareja, Leidy Laura (2017). Violencias epistémicas y acciones pedagógicas de resistencia en el Estado multicultural. Revista Controversia, 209, 41-90.

Fecha de recepción: 10 de julio del 2017.

Fecha de aprobación: 13 de octubre del 2017.

\section{Introducción}

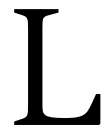

as reflexiones que presento en este artículo surgen de mi participación como asesora pedagógica en el proyecto "Educación intercultural por la defensa de los derechos de los grupos étnicos", desarrollado por el Centro de Investigación y Educación Popular/Programa por la Paz —Cinep/PPP - en Cartagena, sur de La Guajira y Sierra Nevada de Santa Marta ${ }^{1}$ desde el año 2016. En el marco de este

1 Este proyecto tuvo como objetivo contribuir al reconocimiento de los derechos de grupos étnicos en la región Caribe. Para tal efecto, trabajamos con docentes de instituciones educativas de primaria y secundaria, líderes y lideresas de organizaciones sociales, jóvenes investigadores e investigadoras. Las y los primeros (docentes) fueron formados en educación intercultural, a través de un diplomado. Paralelo a este proceso de formación diseñaron, implementaron y sistematizaron Proyectos Integrados de Aula - PIA-. Las lideresas y líderes participaron en un proceso de formación política a través de talleres, en los que se procuró brindar herramientas para la defensa territorial. Los y las jóvenes se formaron en investigación local participativa; a partir de esta formación, desarrollaron investigaciones sobre sus territorios, en donde exponen la situación de los grupos étnicos en la región. 
proyecto, un grupo de asesoras pedagógicas acompañamos a maestros y maestras de estos tres territorios - que llamamos nodos- en el diseño, implementación y sistematización de Proyectos Integrados de Aula ${ }^{2}$ (en adelante PIA) que se hicieron preguntas por las diferencias étnicoraciales y de género en la escuela.

Uno de los objetivos que nos propusimos en esta experiencia fue desarrollar una investigación de corte etnográfico que nos permitiera identificar las apropiaciones y tensiones que experimentaban los sujetos con los cuales trabajamos, frente al enfoque intercultural y de género, referentes estos de nuestra acción académica y política. Este artículo muestra resultados parciales de esta investigación, centrados en las experiencias de maestros y maestras.

Para desarrollar la indagación, utilizamos como material de análisis los documentos producidos durante el desarrollo del proyecto (2016-2017) tales como líneas base, diarios de campo de las asesoras pedagógicas, relatorías de talleres, algunos PIA y sus respectivas sistematizaciones. De igual forma, a partir del mes de mayo del año 2017 iniciamos un proceso de recolección de información en campo, con criterios más específicos, sobre personas y espacios que nos resultaban claves para identificar las apropiaciones y tensiones frente a los enfoques mencionados. Lo anterior lo hicimos a través de observaciones participantes, entrevistas semiestructuradas y grupos focales ${ }^{3}$.

2 Los Proyectos Integrados de Aula - PIA - se entienden como una propuesta pedagógica constructivista que trabaja alrededor de una pregunta de interés elaborada con los y las estudiantes, la cual es abordada desde diferentes áreas. Desde esta perspectiva, se dejan de enseñar áreas específicas del conocimiento y se proponen reflexiones que abordan diferentes campos disciplinares.

3 En el caso de la observación participante, el equipo de investigación participó en talleres de sistematización de experiencias pedagógicas. Realizamos veintiún entrevistas semiestructuradas a maestros y maestras a través de las cuales recolectamos información sobre su trayectoria y prácticas pedagógicas, así como de su experiencia subjetiva como hombres y mujeres afrodescendientes, negros (as), palenqueros (as), indígenas, mestizos (as) o sin identificaciones étnicas; de igual forma, las entrevistas arrojaron información sobre experiencias de racismo y discriminación vividas por los y las docentes. En cuanto a los grupos focales, se realizó uno en cada nodo y en ellos se discutió cómo entendían maestros y maestras la interculturalidad y la perspectiva de género, así como también las posibilidades, dificultades, tensiones y retos que encuentran en sus respectivas instituciones para aplicar estas perspectivas. 
Esta investigación, aún en curso, nos ha enfrentado a una gran complejidad analítica en tanto que el proyecto abordó tres territorios de la región Caribe, habitados por maestros y maestras de diversos orígenes: indígenas, palenqueros, negros, afrodescendientes, mestizos y personas sin identificación étnica. Ahora bien, estos grupos étnicos tienen trayectorias históricas, políticas y académicas diferentes que se deben considerar para comprender sus agendas político-educativas, demandas y conflictos. En ese orden de ideas, el reto de análisis de esta exploración reside, sobre todo, en que ninguna lectura, en ninguna clave, es susceptible de homogenización. Es decir, no podemos leer de igual forma a maestros y maestras bien sea en clave de género, etnia-raza o territorio. Cuando hablamos de las maestras - mujeres - encontramos que estas pueden ser indígenas, palenqueras, negras, afrodescendientes, mestizas o no se identifican étnicamente. De igual manera, cuando hablamos de mujeres afrodescendientes -para continuar con el ejemplo- unas habitan el sur de la Guajira y otras en Cartagena; por lo tanto, enfrentan experiencias y apuestas políticas distintas conformes con los territorios que habitan. De esta forma, no son iguales por ser mujeres, así como no son iguales por ser afrodescendientes. Así, entendemos que la experiencia étnica es moldeada por el género y la experiencia de género también es moldeada por la posición étnico-racial, y ambas por el territorio. El presente artículo muestra los resultados parciales del riesgo analítico que decidimos asumir.

\section{La tensión que aborda este artículo}

Como equipo de investigación encontramos clave preguntarnos no solo por las apropiaciones frente al enfoque intercultural y de género, sino también por las tensiones, entendidas como una experiencia conflictiva, como un desacuerdo que no alcanza consenso y permanece irresuelto; algunas de estas tensiones ocurren en el marco de relaciones desiguales de poder. En este contexto, la tensión supone que los sujetos conviven en una permanente resistencia, controversia y oposición que, insistimos, siempre está vigente. 
En nuestra indagación hallamos una profunda tensión entre la etnoeducación, la educación propia y las políticas educativas. Precisamente sobre esta problemática versa este artículo. Un ejemplo de ello es cómo en el proceso de diseñar e implementar los PIA, para un número importante de maestros y maestras, las pruebas Saber — aplicadas por el MEN a los y las estudiantes de tercero, quinto, noveno y undécimo grado para 'medir' la calidad educativa - constituyen una de las principales dificultades para trabajar a partir de dicha metodología, pues estas pruebas estandarizadas no tienen en cuenta especificidades de estas comunidades. En ese sentido, los PIA constituyeron no solo una metodología, sino un escenario en el que emergieron contenidos no incorporados en los currículos oficiales de varias de las instituciones educativas con las que trabajamos. Dicho en otras palabras, los PIA ofrecieron una oportunidad para cuestionarnos sobre los conocimientos hegemónicos que circulan en el aula, y, además, desde dónde han sido producidos y cuáles son aquellas presencias (o ausencias) que no registran en la escuela.

Preguntas como: ¿a quién enseño?, ¿qué enseño?, ¿cómo lo hago?, ¿con qué materiales?, dieron lugar a reflexiones que situaron las identidades de las y los estudiantes en un punto clave de la acción pedagógica, ya que, a partir del reconocimiento de que estas identidades implican discusiones de orden político, económico, ambiental, territorial y cultural, se fueron definiendo contenidos, metodologías y herramientas de diversificación didáctica para desarrollar en el aula. Sin embargo, muchos maestros y maestras entraron en conflicto, puesto que el currículo oficial define como irrelevantes e improductivos - en función de las pruebas Saber - muchos de los contenidos y estrategias metodológicas que emergen a partir de los PIA. Lo anterior condujo a un grupo nutrido de estos maestros y maestras - sobre todo a quienes no estaban vinculados a instituciones etnoeducativas - a escindir su práctica entre ese currículo oficial — con el que se procura responder a las pruebas- y los contenidos emergentes de los PIA. 
Hemos concluido que, al hablar de las pruebas de Estado se pone de manifiesto que la episteme dominante del sistema educativo colombiano subalterniza otras epistemes. En ese sentido, en este artículo argumentaremos que, en el marco de la relación entre los grupos étnicos y el Estado multicultural, la etnoeducación y la educación propia - como políticas educativas- no transforman la posición epistémica desigual que ocupan los grupos étnicos en el sistema educativo colombiano. Esta discusión se inscribe en la compleja tensión entre unidad nacional, diferencia y formas legítimas de educación; es decir, hace referencia a lo que es "considerado como válido para la educación escolar, las decisiones acerca de qué, cómo y con quiénes debe ser aprendido lo que es considerado relevante dentro del proyecto hegemónico de nación" (Restrepo y Rojas, 2012, p.171). Así, nos enfrentamos aquí a las conflictivas relaciones entre unidad y diferencia, mismidad y alteridad (Rojas, 2011).

Encontramos que los proyectos etnoeducativos no generan cambios en la idea de un currículo nacional homogéneo. Aunque en apariencia para la política educativa son legítimos otros proyectos curriculares que operan a partir de las aspiraciones y planes de vida de los grupos étnicos, lo cierto es que ese currículo nacional-homogéneo, eurocéntrico-colonial, se convierte en el único referente de la evaluación; por lo tanto, los grupos étnicos no lo afectan, pero tampoco pueden prescindir de él.

Ahora bien, conviene aclarar que en esta discusión reconocemos que la etnoeducación surge como un proyecto político de los grupos étnicos, aunque con trayectorias diferentes para comunidades indígenas y negras. Como anotan Castillo y Caicedo (2010), la disputa por la educación en el caso indígena emerge con fuerza en la década de los setenta como parte de un movimiento agrario, en lo que se denominó recuperación de las tierras de resguardo. De igual manera, para estos pueblos, la etnoeducación supuso un proyecto político que cuestionaba el control católico de las escuelas y demandaba el derecho a la autonomía educativa. Estas luchas dieron lugar a la creación de una normatividad en 
materia de educación para estos grupos étnicos entre las décadas de los setenta y los noventa.

La demanda de autonomía educativa ha sido central en la agenda política del movimiento indígena en Colombia. Esta lucha lo ha llevado a situarse desde perspectivas como la educación propia, entendida como una forma de afirmación política ante el Ministerio de Educación Nacional. Este concepto aboga por el control pleno de los recursos y de los mecanismos educativos escolares en territorio indígena (Castillo, 2008, p.21). Por su parte, para las comunidades negras, la etnoeducación se desarrolla en el marco de una disputa más amplia por el reconocimiento de su estatus étnico, reconocimiento que solo se logra jurídicamente con la Constitución de 1991 y, de manera específica, con la Ley 70 de 1993.

Sin embargo, la tensión que desarrollaremos aquí parte de examinar también la institucionalización de la etnoeducación como parte de las políticas de reconocimiento que gestiona el Estado multicultural, y que actúan en articulación con políticas neoliberales. En este contexto, la etnoeducación parece haber perdido el valor simbólico y político que tuvo en sus inicios y se ha convertido en un derecho cultural reducido a la propia discursividad institucional (Castillo, 2008, p.21).

Igualmente, problematizaremos el hecho de que —en la lógica multicultural- la etnoeducación no desestabiliza las desigualdades epistémicas, sino que las reproduce. La institucionalización de la etnoeducación no combate las injusticias cognitivas, que se soportan en la idea de que existe un solo conocimiento válido (Boaventura de Sousa Santos, 2011). Para de Sousa Santos no hay justicia global sin justicia cognitiva, aludiendo con esto al conjunto de conocimientos alternativos que han sido destruidos por el poder hegemónico del conocimiento científico (citado en Castillo y Caicedo, 2016).

Empero, abarcaremos algunas de las acciones pedagógicas de resistencia que están desarrollando maestros y maestras en medio de esa tensión con las políticas educativas nacionales. En ese sentido, esta 
reflexión se inscribe en una disputa por el campo del conocimiento, en tanto que entendemos que la dignidad de los grupos étnicos supone reconocer las epistemes construidas por ellos en relaciones de igualdad con otras epistemes.

\section{El imperativo de apropiar el universo simbólico- cultural del Otro que es el Yo de la nación}

Camila ${ }^{4}$ es una docente wiwa que enseña a sus estudiantes el valor sagrado de las piedras que, en su cultura, tienen vida. Al igual que ella, cuando César conversa con niños y niñas sobre el ecosistema, insiste en que para el pueblo wiwa todo tiene sentido y las piedras brindan sabiduría, enseñanza, respeto y, por lo tanto, no pueden rayarse. Sin embargo, en el primer Encuentro Regional de Educación Intercultural que realizamos en el municipio de Barrancas (Guajira) ${ }^{5}$, Camila manifestó el contraste de este principio wiwa con el currículo oficial que se evalúa en las pruebas Saber, en el cual las piedras registran como cosas sin vida que solo tienen valor de uso.

Conscientes de que sus estudiantes deben presentar las pruebas Saber en diferentes momentos de su vida escolar, los educadores wiwa debe movilizarse entre dos proyectos curriculares: el propio y el oficial. Esos dos proyectos expresan la tensión entre el nosotros wiwa y el otro: Occidente, hermano menor, el yo nacional. Para los y las docentes wiwas el currículo oficial expresa la episteme de Occidente, pero, debido a que es el referente de la evaluación, debe ser aprendido.

Encontramos en la práctica que, por efecto de la evaluación y por el ingreso de niños y niñas de grupos étnicos a las escuelas llamadas

4 Los nombres de las personas entrevistadas han sido cambiados.

5 Este fue el primer seminario realizado en el marco del proyecto que da lugar a este artículo. En este participaron docentes, líderes/lideresas de organizaciones sociales y jóvenes investigadores e investigadoras que han venido participando de procesos de formación política e investigación local. 
mayoritarias, ${ }^{6}$ estos y estas deben aprender la episteme y el universo cultural-simbólico del Otro occidental y, para el caso específico de nuestro país, el universo andino, blanco-mestizo, de clase media. Hallamos igualmente que, en la implementación de los PIA —-formulados por maestros y maestras wiwas y que pretenden fortalecer la educación propia-, el conocimiento propio adquiría sentido a partir de su diferenciación con el conocimiento occidental, en un ejercicio de conocerse/ afirmarse a través del otro, a partir de permanentes narrativas de distinción, contrastes, exclusiones, establecimiento de límites y fronteras.

Si bien lo anterior hace parte del juego estratégico de responder a las pruebas estatales -es decir, el imperativo de conocer la episteme occidental presente en la política de conocimiento del sistema educativo-, también constituye un ejercicio de formación y reafirmación identitaria en el cual el sujeto wiwa va incorporando su lugar de alteridad y el lugar subalternizado de su propia episteme, en tanto que debe aprender que la suya no es la evaluable. En ese orden de ideas, los estudiantes deben asimilar que las piedras tienen y no tienen vida. Esto representa de por sí una violencia, pues la prueba le impone una episteme que, además, tiende a la cosificación, una episteme de muerte y asesina. Entonces, las políticas educativas se sitúan en el terreno de un conocimiento incompleto y jerarquizante que no considera la posibilidad de "vida en la piedra”, pero, al mismo tiempo, se asume como válido universalmente.

En los PIA desarrollados por maestros y maestras wiwas hay una permanente pregunta y una apuesta pedagógica por lo tradicional, lo propio, que debe ser fortalecido y recuperado. Se parte del supuesto de que años de violenta intervención de la iglesia-docente, como la nombra Castillo y Rojas (2005), produjo afectaciones en la identidad cultural que hasta hoy se mantienen. Por lo tanto, la educación propia opera como una suerte de nueva intervención para formar y recuperar esas identidades.

6 Hago referencia, sobre todo, a niños y niñas del pueblo wiwa y wayúu. 
Sin embargo, encontramos que esas intervenciones de recuperación identitaria actúan en articulación y muchas veces son funcionales a las políticas educativas. De acuerdo con Rojas (2011),

[...] la etnoeducación se ha constituido en espacio de conceptualización de la multiculturalidad y de definición de los mecanismos para administrarla. Como política educativa, contiene ejercicios de representación y producción del otro en tanto que define quiénes son los grupos étnicos, cómo estos deben ser educados y el tipo de relación que deben establecer con los conocimientos y poblaciones que son considerados como no étnicos. Los proyectos curriculares que se desarrollan a partir de la etnoeducación están diseñados de tal forma que los sujetos que en ella se educan actúen de acuerdo con una condición de radical alteridad respecto de las sociedades de las que hacen parte; es decir, para que se gobiernen a sí mismos en nombre de la cultura y la diferencia (p.190).

Entonces, esas políticas educativas que operan desde lógicas multiculturales son lugares de producción de una alteridad étnica que, finalmente, no representan amenaza para la matriz racista, clasista, andina, patriarcal de las políticas de conocimiento. Así, se avala la enseñanza de los conocimientos propios, pero restándoles, al mismo tiempo, potencial epistémico para incorporarse y afectar esos conocimientos del currículo-nacional homogéneo expresados en los estándares básicos de competencias que, a la postre, son los evaluables.

Incluso, encontramos evidencia de la política educativa como lugar de producción de la alteridad étnica desde la experiencia vital de maestros y maestras. Indagar por sus historias vitales nos permitió, a su vez, historizar sus propias identidades y rastrear en sus trayectorias ejercicios de violencia epistémica e injusticias cognitivas. Pensemos, por ejemplo, en la experiencia vital de Luis, un hombre wiwa de treinta y tres años de experiencia como maestro, en cuya narrativa encontramos dos asuntos relevantes: en primer lugar, su historia comunitaria y familiar da cuenta de una serie de intervenciones coloniales/nacionales que 
le hicieron posible ingresar al sistema educativo en calidad de maestro - estamos refiriéndonos específicamente a su castellanización-; en segundo lugar, parte de su experiencia da cuenta de un proceso de etnización que también es producto de políticas educativas, en el marco de las relaciones entre pueblos indígenas y el Estado nación que precedió al Estado multicultural —nos referimos específicamente a la recuperación de la lengua-. Dicho en otras palabras, perder la lengua y recuperarla fue producto de intervenciones del proyecto civilizador colonial y del proyecto nacional republicano. En ese sentido, encontramos que se hicieron maestros wiwas aquellos sujetos que ya habían sido intervenidos por el proyecto civilizatorio y que podían garantizar la relación entre el Estado y las poblaciones que aún permanecían en 'estado salvaje', es decir, que no habían incorporado los mínimos de la nación, como el habla, lectura y escritura del castellano.

La castellanización de Luis, según relata, actúa desde la intervención misma del cuerpo de su madre a través del orfelinato, considerada durante mucho tiempo como la mejor estrategia para civilizar a los indios. Para la iglesia-docente, como parte del proyecto civilizatorio de poblaciones indígenas, moralizar equivalía a escolarizar. De manera particular, con la recatolización del sistema educativo que supuso el gobierno de Núñez - y ante la incapacidad del Estado para extender su autoridad y soberanía en todo el país - se otorgó a la Iglesia la tutela de las poblaciones ubicadas en vastas extensiones periféricas de la geografía nacional habitadas por indígenas considerados salvajes, esto es, por no ser hispanoparlantes y desconocer la religión cristiana (Roldán y Gómez, citados en Castillo y Rojas, 2005, p.65).

La castellanización de las mujeres, al ser las encargadas de reproducir la cultura, tendría un efecto castellanizante en su prole.

Nosotros descendemos de una familia de aquí de Potrerito, por donde van a cruzar mañana, y para allá fue mucho en la época que vinieron los orfelinatos, que hubo por allá por la Sierrita, entonces aculturizaron mucho, 
entonces se manejaba más que todo el castellano, mi mamá desciende de esa familia y ella incorporó el castellano de esa manera (Luis, docente wiwa, comunicación personal, 14 de junio de 2017).

La misión de la iglesia-docente, a cargo de los capuchinos, intervino a Luis para enseñarle la lectura y la escritura en castellano, lengua que ya hablaba. Según su relato, la presencia de esta misión en Bernaka fue solicitada por la misma comunidad, quien encontraba necesario aprender la lectura y la escritura del castellano para interlocutar con el Estado.

En 1975 una comunidad en Cherúa en la colonia las misiones capuchinas, ellos por petición de un indígena wiwa que fue al Ministerio de Educación que ellos querían acercarse a la educación porque vieron que era muy importante aprender a leer y escribir para poder interlocutar con el gobierno, y fue un Mayor que fue a una reunión donde los hermanos arahuacos, vio que los arhuacos, ellos se desenvolvían en una relación que estaban haciendo con personas del gobierno, y por esa razón él se vino muy motivado y le propuso a la comunidad y así él podría ir hasta Bogotá a solicitar [...] La idea del profesor cuando vino, él pensó en poner esa religión. Entonces había unos señores de la comunidad muy conocedores de la parte cultural y ellos le dijeron, le propusieron que ellos necesitaban que los niños aprendieran a leer y a escribir, a sacar cuentas, y para tener relaciones con el Estado. Solamente le propusieron eso, pero le dijeron, nada de religión, no le vaya a hablar de eso, no, para eso nosotros tenemos nuestra cultura (Luis, docente wiwa, comunicación personal, 14 de junio de 2017).

Es en este contexto en donde Luis aprende a leer y a escribir en castellano, cabe anotar que ingresó a la escuela a la edad de once años. En la década de los ochenta, participa en unos cursos de castellanización con el pueblo arhuaco, dichos cursos posibilitaron su vinculación posterior como docente, una vez los capuchinos fueron expulsados de la Sierra Nevada de Santa Marta. En esta misma década, los indígenas wiwas de la Sierra Nevada de Santa Marta sintieron los impactos políticos de los movimientos sociales étnicos que se gestaban en Colombia y en Latino- 
américa, estos incluyeron en su agenda política el campo de la educación. En la década de los setenta, los movimientos indígenas empiezan a demandar autonomía en materia educativa. Como hecho importante se constituye el Consejo Regional Indígena del Cauca - CRIC-, que incluye en su plataforma política la formación de maestros indígenas para educar conforme con su situación específica y en su lengua.

En ese momento estaban los indígenas en su apogeo, en su movimiento, en política, reclamando muchas cosas al Estado, no los de la Sierra, pero los indígenas por allá del Cauca, del Amazonas. Entonces ya habían [sic] acuerdos con el Ministerio que en ese momento sale el decreto 1142, que fue impulsado por los arhuacos, y ellos hacen que eso sea un reglamento, donde decía que ellos, los pueblos indígenas podían ejercer su propia educación y las comunidades podían decir a quién podían nombrar (Luis, maestro wiwa, comunicación personal, 14 de junio de 2017).

Tal como relata Luis, la acción del CRIC fue importante en la promoción de acciones políticas para el reconocimiento de derechos educativos especiales de este grupo étnico, conforme con sus particularidades culturales y lingüísticas. Resultado de la incidencia política del CRIC, se dio la promulgación del Decreto 1142 de 1978, en el cual se habla por primera vez de etnoeducación y se plantea la autonomía de los grupos étnicos para diseñar sus proyectos curriculares, mantener su lengua (bilingüismo) y a elegir sus propios maestros (García, 1999; Castillo, 2008). De esta manera, los grupos étnicos se posicionan como un actor que disputa su participación y legitimidad en la formulación de políticas públicas nacionales.

Luis se hace docente en 1984, cuando tenía diecisiete años, y recuerda como un hecho clave de su ingreso a la docencia la expulsión de los capuchinos de la Sierra Nevada. En 1982, los indígenas arhuacos tomaron las instalaciones de la Misión de Nabusimake, administrada por los capuchinos desde 1916, demandando la expulsión de los misioneros. Como resultado, el Gobierno y los indígenas pactan la terminación del 
contrato firmado entre el obispo y el gobernador de Valledupar y Cesar sobre educación contratada para la comunidad arhuaca (ONIC, citada en Castillo, 2011). Aunque aún estaba vigente la conservadora Constitución de 1886, el Gobierno nacional tuvo que deshacer el contrato con la Santa Sede en los territorios de la Sierra Nevada de Santa Marta. Esta acción de los arhuacos constituye un hito histórico, pues es la primera vez en la historia del país que, producto de una movilización de este tipo, se expulsa a una comunidad religiosa del territorio (Castillo y Caicedo, 2008).

En 1984 - cuando Luis inicia su experiencia como maestro- tenía cuatro años de vigencia el Decreto 85 de 1980, el cual establece en su primer artículo que en las zonas rurales de difícil acceso y poblaciones apartadas, podrá nombrarse para ejercer la docencia en los niveles preescolar, básica primaria y básica secundaria personas que acrediten título de bachiller en cualquier modalidad, siempre y cuando no existiera personal titulado o en formación que estuviera en capacidad de prestar el servicio requerido. Sin embargo, establece que para las comunidades indígenas podía nombrarse personal bilingüe que no reuniera los requisitos académicos antes previstos. En este contexto, empieza a existir el maestro indígena para las poblaciones wiwas.

El nombramiento de docentes wiwas asignados a territorios periféricos de la Sierra Nevada de Santa Marta estuvo a cargo de la Secretaría de Educación de Valledupar, entidad que tuvo como referente a jóvenes de este grupo étnico que habían realizado el curso de castellanización; sin embargo, Luis no era hablante del dumuna. Es posible pensar que el primer criterio para el nombramiento era un docente indígena capaz de articular los grupos étnicos con el Estado-nación al haber incorporado la lengua oficial, el castellano.

En esa época, a mí no me pidieron mi consentimiento, si quería. No quería. Es porque sabía leer y escribir, fue que supieran leer y escribir, porque así lo habían dicho, y supiera hablar la lengua podía ser un docente indígena, en ese momento (Luis, docente wiwa, comunicación personal, junio 14 de 2017). 
Ocurren dos experiencias en esta producción del maestro indígena que se leen desde la narrativa de Luis. Por un lado, docentes wiwas fueron enviados a territorios que no habían sido castellanizados del todo. Por el otro, en este momento histórico, el maestro indígena asume la misión de castellanizar, al tiempo que se interviene a sí mismo étnicamente aprendiendo la lengua que, justamente, el proyecto colonizador, republicano y de nación le había hecho perder. La experiencia de maestro indígena supone entonces una producción identitaria como indígenas wiwas, en la que este sujeto que se está produciendo se propone para sí mismo la recuperación de lo propio. Ese aspecto identitario que antes había sido borrado para civilizarlo e integrarlo a la nación, ahora se produce y se marca en el contexto de las políticas educativas para grupos étnicos.

Luis fue enviado a Sinca (Cesar) y esta comunidad no lo leyó como un par étnico, sino como un nuevo misionero, un enviado de la educación occidental-occidentalizante. En principio, no hablaba la lengua, lo que ya implicaba una distancia con una comunidad que sí era hablante. El aprendizaje de la lengua, en este inicio, surge como una necesidad comunicativa. Sin embargo, las familias en Sinca empiezan a considerar que las relaciones con el Estado y con los otros - no indígenas- exigían que los niños hablaran ‘bien’ el castellano.

[...] yo lo asumí [el nombramiento], y en ese momento casi tampoco no hablaba la lengua bien, entonces eso era lo que a mí me incomodaba, porque como debía ser hablante, entonces así eso me incomodaba. Bueno, entonces es cuando me nombran en ese momento y me mandan a una comunidad que llaman Sinca. Y cuando llego allá, la comunidad no quería docente porque era en esa época muchas comunidades por aquí, aferradas, no eran de la educación de Occidente, y habían [sic] dos familias que dijeron que ellos sí querían; entonces me quedé con esas dos familias [...] entonces los niños ya eran hablantes de lengua, y entonces como yo no era casi hablante de la lengua, entonces me vi que tenía que hacer un esfuerzo de hablar la lengua para comunicarme. Entonces en eso yo me interesé de aprender a hablar la 
lengua con los mayores y me dio buen resultado porque en un año ya aprendí a hablar la lengua (Luis, comunicación personal, 14 de junio de 2017).

En la labor de este maestro indígena se expresa la correlación de fuerzas hegemónicas y contrahegemónicas, que implicaba asimilar y "normalizar" la lengua dominante, así como mantener y preservar la lengua dominada (Hamel, citado en Dietz y Mateos, 2011, p.104). Dietz señala que la labor del maestro bilingüe desde la década de los años setenta del siglo pasado ha consistido en castellanizar e integrar a los indígenas al proyecto nacional. Esta ha sido una tarea de mediación entre las comunidades y las instituciones gubernamentales, así como también el manejo y recepción de las políticas educativas nacionales en los ámbitos comunitarios o regionales (2011, p.105).

No hablar el dumuna antes de hacerse maestros indígenas wiwas es una experiencia que comparten otras personas que ingresaron al Magisterio en la década del dos mil, tal es el caso de Yanis. Ella recibió una enseñanza en castellano y sus estudios de bachillerato los cursó en San Juan del Cesar (Guajira), en una escuela mayoritaria que le reforzó el uso del español. Al igual que Luis, Yanis aprende el dumuna cuando se enfrenta en Surimena (César) a un grupo de niños y niñas, y sus respectivas familias, para quienes esta era la primera lengua. Desde su ingreso al Magisterio, su labor como maestra establece como uno de sus objetivos fundamentales la lectura y la escritura tanto en dumuna como en castellano.

En esa comunidad [Surimena] son bastantes hablantes de la lengua, de dumuna, me sirvió mucho para yo, también, porque yo muy poco, o sea, yo la entiendo y la hablo varias palabras, pero tampoco la pone en práctica, pero con los niños ya me tocaba por obligación. No tuve dificultad con ellos, ese aprendizaje fue muy bueno porque yo podía hablarles dos idiomas (Yanis, docente wiwa, comunicación personal, 13 de junio de 2017). 
El tema del bilingüismo en las instituciones etnoeducativas o de educación propia presenta una serie de problemáticas, referidas tanto a las pruebas Saber, como también al ingreso de estudiantes indígenas a otras instituciones educativas que no tienen este enfoque, para dar continuidad a sus estudios de educación media y superior. Aquí se ejercen otra serie de violencias epistémicas.

De manera particular, para las docentes wayúu - cuyos estudiantes, por lo general, continúan sus estudios de educación media en instituciones "mayoritarias" - hablar y escribir español constituye una meta básica de aprendizaje para el ingreso y sobrevivencia en otros mundos escolares que operan bajo políticas de conocimiento monolingües. Maestras como Norma - mujer wayúu para quien el wayuunaiki fue su primera lengua-, si bien consideran imperativo el aprendizaje del castellano, no asumen de manera transparente la noción de hablarlo "correctamente"; asumen que este debe ser hablado desde el ser wayúu, es decir, desde un lugar étnico que le da un habla específica a la "lengua oficial". Este lugar, para Norma, debe ser reconocido y no negado o avergonzado.

En San Francisco hay una particularidad que ha sido fortaleza por un lado para la educación propia, pero debilidad por otro lado. Y en esta comunidad los niños son monolingües en wayuunaiki. Y, por ejemplo, yo como docente de los niños más grandes siempre hago como el esfuerzo de que hablen en español y les hablen español. Se enseña en wayuunaiki, pero he dado el énfasis en español porque ellos no son niños de prescolar; cuando están en prescolar, wayuunaiki. Porque yo quiero que ellos hablen en español, no que olviden el wayuunaiki, pero tienen que hablarlo porque hubo una dificultad el año pasado, y es que muchos niños cuando les hicieron como entrevistas para pasar el bachillerato, no dieron por qué, no sé... les da pena que lo pronuncien mal. No importa, o sea, tú no estás hablando mal el español, tú lo estás hablando desde tu wayuunaiki. Porque es que es otra, lo que pasa es que educamos a nuestros niños en wayúu, pero hay es que educar a los arijunas. A que si tú dices, por ejemplo: un libro, en wayuunaiki es 
Karalou'takat, es femenino. Y tú dices el libro y el libro es masculino, el libro. Entonces si una niña wayúu dice, la libre o la papel, qué hace el arijuna, se burla. ¡Ayy! No sabe hablar. Entonces lo que hacen los niños wayúu, se cohíben. Van a burlarnos, no quiero decirlo. Tanto así que yo he visto a mis estudiantes que hacen como el intento y ellos mismos como que miran pa' todas partes o se ríen ellos solos, u otro le dice, "ayy... habló español" (Norma, docente wayúu, comunicación personal, 26 de junio de 207).

En el documento del MEN que presenta los estándares básicos de competencias en lenguaje, se advierte la importancia de ser competente lingüísticamente para "desempeñarse en la vida”; al tiempo, se anota que "cuando en estos estándares se habla de lenguaje se está haciendo alusión a la lengua castellana” (MEN, 2010, p.18). En este documento se entiende la lengua castellana como un sistema simbólico, lo que quiere decir que tiene "implicaciones en los órdenes cognitivo, pragmático, emocional, cultural e ideológico” (MEN, 2010, p.24). Partamos entonces del supuesto de que toda lengua es en sí misma un sistema simbólico, es decir, el dumuna y el wayuunaiki, para el caso de los pueblos wiwas y wayúu respectivamente, constituyen sistemas simbólicos. En efecto, para Norma

Lo propio y todo está en la lengua. La concepción que tú tengas, si tienes al wayuunaiki como segunda lengua nunca va a ser igual a alguien que tenga el wayuunaiki como su primera lengua, si lo aprendió primero [...] hay unas cosas que son tan difíciles, no se pueden traducir. Solamente el que sabe wayuunaiki puede entenderlo. Y son conceptos como tan espirituales, no sé qué otro nombre darle. Pero el ser wayúu tiene una conexión muy estrecha con la lengua, para mí es fundamental (Norma, docente wayúu, comunicación personal, 26 de junio de 2017).

En ese sentido, — bajo la lógica de unos estándares básicos en lenguaje- los niños y las niñas de los grupos étnicos deben incorporar, en ese momento vital, el sistema simbólico-cultural propio y el del Otro —su Otro- que es el Yo de la nación. 
A menudo, encontramos en maestros y maestras un cuestionamiento a las pruebas Saber que presentan los y las estudiantes de tercero y quinto por el "complejo lenguaje" en el que estas son diseñadas y que resulta incomprensible para niños y niñas. En el ejercicio de caracterización de maestros y maestras realizado al inicio del proyecto "Educación Intercultural", encontramos que en contextos como el cartagenero los docentes suelen considerar que el nivel de la prueba supera lingüística y cognitivamente a sus estudiantes, ubicados en contextos populares empobrecidos. Sin embargo, aún no hay una lectura del sistema de evaluación en clave de injusticias cognitivas y violencias epistémicas, pues no se considera que niños y niñas deben incorporar el sistema simbólico del Otro - andino, blanco-mestizo, de clase media- en unos tiempos específicos. Las maestras viven con la sensación de que niños y niñas no han aprendido lo que deberían en el tiempo establecido por el sistema educativo, frente al cual siempre están en desventaja; pues este considera que son dichos estudiantes los que avanzan “lento” y no que la prueba los violenta.

Nosotras contamos con un plan de área focalizado con los temas que se tienen que llevar a cabo. Nosotras en ocasiones reestructuramos eso dependiendo de las dificultades que se presenten en el aula, por ejemplo, deberíamos estar en sumas llevando, pero los niños no están en ese periodo, no han aprendido a contar bien del uno al diez, no podemos pasar al segundo plano, nos toca reestructurar y seguirnos por el proceso de aprendizaje que ellos llevan. El plan lo hemos construido de acuerdo con el contexto, a las necesidades de ellos. Aquí estamos a paso de cangrejo, avanzamos un paso y en la casa retroceden dos. Vienen con deficiencias, lo que más se les da a ellos es lecturas comprensivas, análisis de texto, producción textual, vocabulario, lo que exige las pruebas Saber. A los niños se les da algún tema, se les dan las pautas, ciertas palabras, y a través de ellas producen un texto de su imaginación. Los contenidos están en el currículo, se establecen los temas en la planeación, se establece lo que se va a dar desde preescolar hasta once. En ciertos casos hacemos modificaciones, trabajamos el libro de competencias, el PTA, ese libro en ocasiones viene muy elevado para los 
niños y los adaptamos a sus niveles, condición, o a sus contextos, más bien. En castellano estamos cogiendo a los niños bastante atrasados, el año pasado no alcanzaron a ver las palabras normales: mamá, papá, loma. Este año ya deben repasar combinaciones, pero yo no pude repasar, yo tuve que enseñarlas. Lo importante es que aprenda a leer, en este momento ya están, bueno algunos cancaneando, pero la mayoría ya está leyendo (Documento de caracterización, Institución Educativa Liceo Bolívar-Cartagena, proyecto “Educación intercultural por la defensa de los grupos étnicos”, Cinep/PPP).

Preocupados por los resultados de la prueba en el área de lenguaje, para maestros y maestras se vuelve imperativo enseñar vocabulario. Aun cuando reconocen que el vocabulario de la prueba responde a contextos andinos, se ven obligados a enseñar los códigos lingüísticos del Otro. En tanto que cada lengua implica un sistema simbólico - y así lo reconoce el MEN- y en tanto que el lenguaje permite la producción de sentido, es decir, representar, encontramos que maestros y maestras - comprometidos con el buen resultado ante la prueba- destinan su trabajo pedagógico a establecer una relación entre conceptos y lenguaje en los términos del sujeto dominante/privilegiado contenido en la prueba. Tenemos entonces que es el sujeto de la alteridad quien debe realizar ejercicios de traducción, el sujeto de privilegio no está obligado a traducir, él debe ser traducido. En ese sentido, sus formas particulares de interpretar el mundo, de representarlo, vistas a sí mismas como referentes comunes de entendimiento, son las que deben ser aprendidas.

La experiencia de la prueba, según lo narrado por los y las docentes, indica que para los estudiantes no existe una clara relación entre "mapas conceptuales, sistemas de lenguaje y códigos que gobiernan la relación de traducción entre ellos" (Hall, 1997). Dicho en otras palabras, los estudiantes no relacionan determinadas palabras con determinados conceptos o quizá lo más correcto es decir que el estudiante no comparte esa relación de traducción entre palabras y conceptos porque, como se ha insistido, esa relación está establecida en los términos de un sujeto específico que él no encarna. 
He aquí un ejercicio violento: en un periodo vital en el que niños y niñas están aprendiendo las relaciones entre conceptos y códigos lingüísticos de su contexto inmediato, se le evalúa según las representaciones de otro. De esta forma, los códigos lingüísticos y variantes dialectales del otro-étnico se deslegitiman, porque no tienen alcance nacional y porque se considera "mal hablar o mal escribir" (en el caso de las variantes dialectales).

Lo anterior ha conducido a que la literatura de los grupos étnicos sea marginalizada en varias de las instituciones educativas con las que trabajamos, porque no contribuye al propósito de hablar, leer y escribir correctamente el castellano. La literatura de escritores afrodescendientes del Caribe y el Pacífico suele excluirse de la literatura oficial que se trabaja en las aulas porque, intencionadamente, "escriben como hablan". Pensemos por ejemplo en Canción del Boga Ausente de Candelario Obeso

Qué trijte que ejtá la noche,

la noche qué trijte ejtá:

no hay en er cielo una ejtreya...

Remá! remá!

La negra re mi arma mía, mientra yo brego en la má, bañao en suró por eya, ¿Qué hará? ¿Qué hará?

Uno de los ejercicios de violencia sobre sujetos racializados en el proyecto ilustrado de nación ha sido que este debe separar habla y escritura. Ya de por sí el habla de los grupos étnicos se somete a corrección y burla; sin embargo, puede ser permitida como particularidad, pero - en nombre del sujeto ilustrado- la escritura debe ser homogénea, no puede estar exenta de reglas. Ahora, que literaturas producidas por sujetos racializados se prohíban en la escuela tiene efectos epistémicos importantes 
porque estas dan cuenta de formas particulares de comprender y producir la realidad. Su prohibición le apunta a apropiar una sola forma de conocimiento, lo que supone olvidar otras y, en última instancia, ignorarlas, desconocerlas. Desde la noción de ecología de saberes, De Sousa plantea que todas las prácticas de relaciones entre los seres humanos, así como entre los seres humanos y la naturaleza, implican más de una forma de conocimiento y, por ello, de ignorancia (2011, p.36).

Ahora, entendemos que la episteme de los grupos étnicos implica formas de interpretar e intervenir la realidad que cuestionan la noción de desarrollo del país, frente a la cual los grupos enfrentan sus efectos nocivos territorial y socioambientalmente. Esa noción de desarrollo se soporta también en el saber oficial que circula en las escuelas, en lo que nombra y en lo que oculta, en lo que dice y en lo que silencia, y en cómo interpreta la relación entre los humanos, la naturaleza, el territorio.

\section{Currículo oficial y currículos subalternos}

Al reflexionar sobre su PIA y el currículo de su escuela, Armando, un docente cartagenero que se define a sí mismo como negro, relata: “con el currículo actual nunca vamos a llegar a cuestionarnos sobre lo que busca el proyecto de "Yo soy manglar", porque no hay los espacios donde tú puedas discutir con los estudiantes dentro del currículo de la historia de Cartagena; no existe ese espacio" (Armando, docente de Cartagena, comunicación personal, julio de 2017).

"Yo soy manglar" es un PIA que pone en discusión la segregación racial, la discriminación y el desplazamiento que han sufrido las poblaciones negras que han habitado y habitan las zonas de manglares cercanas al centro histórico de Cartagena. Justamente, este PIA pone en reflexión el modelo de desarrollo fundamentado en el turismo, para el cual las poblaciones negras, afrodescendientes y palenqueras empobrecidas que habitan en las geografías de esta economía siempre han constituido un "problema”. La serie de desplazamientos que esta economía ha 
generado encuentra un hito histórico en 1971 con la reubicación de los habitantes de Chambacú - ubicado a menos de cien metros del centro histórico- hacia el sur de la ciudad, y se extiende en el contexto actual hasta el Cerro de la Popa, territorio en el que se encuentran las instituciones educativas con las que trabajamos.

Que el PIA “Yo soy manglar” tenga un legítimo lugar curricular implica volver a Cartagena, y, específicamente, al Cerro de la Popa, parte fundamental del currículo institucional. Sin embargo, según anota Armando:

tú miras las temáticas que hay en el currículo actual en ciencias sociales y te das cuenta que definitivamente tendría que cambiarse todo, desde mi punto de vista. A nosotros no nos debe interesar Europa, nada más lo necesario para entender la realidad latinoamericana porque somos hijos de Europa también. O sea, Europa no se debe desconocer porque somos producto de Europa, pero hasta ahí. Europa no debe transversalizar todo el proceso educativo de ciencias sociales en el bachillerato. Casi un ochenta por ciento del estudiante de bachillerato está hablando de Europa. Si tú analizas casi desde sexto estamos hablando de Europa, Europa, Europa... llegamos a once y seguimos hablando de Europa, entonces ahí hay una clara cuestión eurocentrista en ese currículo. Todavía en pleno siglo XXI (Armando, docente de Cartagena, comunicación personal, julio de 2017).

A este respecto, la docente Elizabeth Castillo Guzmán plantea lo siguiente: "nosotros le gastamos tres años de secundaria a enseñar la historia de los que nos dañaron la vida, producimos una identificación con el agresor. Es como si los judíos gastaran parte de la vida a enseñar a Hitler" (Castillo, 2016). Castillo cuestionó a maestros y maestras con los que trabajamos frente a la literatura que usamos y sus marcos de referencia. En sus palabras

Mio Cid es el canto a la bandera después de matar a musulmanes. Un país que está construyendo la paz no puede leer el Mio Cid ¿Es eso lo que necesitan aprender nuestros estudiantes? Son tantas mentiras, tantas que, por 
ejemplo, no es justo que los niños en un estado como Canadá estudien el calendario azteca, que es la base para aprender matemáticas, decimales. La trenza tiene una teoría matemática, tiene una imagen mental de lo que puede ser múltiples tropas en la cabeza. Hay un libro sobre historia currículo y trenzado en el Caribe, de Eneiris Navarro Cáceres. Desde el punto de vista cognitivo un muchacho que más aprenda de lo propio vuela más. Esto no lo resuelve un taller o diplomado. Lo más político de nuestro oficio es lo que enseñamos en el aula (Castillo, 2016).

El saber oficial contenido en las políticas de conocimiento gestionadas por el sistema educativo colombiano no son fácilmente deconstruibles por el ejercicio de poder que implica la evaluación. En ese sentido, maestros y maestras -inconformes con ese saber oficial y que han reconocido su carácter incompleto, racista, clasista, occidental- agencian currículos paralelos o desarrollan acciones curriculares de frontera, en los bordes.

\section{Currículos en los bordes}

El currículo que sucede en los bordes no es exactamente un currículo oculto, en tanto que tiene intencionalidad, consciencia, es explícito, aunque no es reconocido por el currículo oficial. Lo desarrollan, fundamentalmente, maestros y maestras vinculados a instituciones que no están focalizadas como etnoeducativas. El currículo que opera en los bordes es un espacio que no debería ocurrir, que está por fuera de la frontera epistémica dominante; por lo tanto, se interpreta como un espacio improductivo. Las metodologías que se despliegan en estos márgenes también son trivializadas y vistas como actividades de ocio que no implican una relación de conocimiento.

Ante el saber oficial, lo que circula en estos bordes se considera un saber prescindible porque no hace parte de los conocimientos institucionalizados que deben ser aprendidos por todos y todas en la nación; por lo tanto, ese saber del margen no tributa al sistema de evaluación. Sin 
embargo, los contenidos que se desarrollan en esos márgenes, situados en epistemes subalternizadas, resultan importantes para la formación política de aquel sujeto que ocupa un lugar de alteridad subalterna. Algunos estudiantes hacen circular estos conocimientos a través de acciones políticas en la escuela, pero también fuera de ella.

Sin embargo, estos proyectos curriculares siguen manteniendo el saber oficial, no lo alteran de manera radical, pues los docentes, estratégicamente, deciden actuar en el borde y promover el saber del margen allí, porque no tienen la opción de evadir el sistema de evaluación, ya que esta toma el saber oficial como referente. Conviene reflexionar sobre quiénes habitan ese borde curricular y lo que ahí se construye. Ese borde es un espacio subalternizado y radicalmente político que hace parte de las fugas y los actos de autonomía construidos en el espacio escolar. Implica la producción de contenido o, en palabras de Armando, crear espacios temáticos que no necesariamente registran en el currículo institucionalizado; son saberes conscientes e intencionados que se reconocen como subalternos. No obstante, ello supone el riesgo de ser sancionado posteriormente a través de la prueba estandarizada. En palabras de Armando:

No existe ese espacio temático en el currículo; entonces, ese espacio temático te lo tienes que inventar tú, desobedeciendo, como te decía ahorita, al sistema, que te la va a cobrar más adelante, porque cuando te pregunten si desarrollaste los temas, o cuando el estudiante se enfrente a la prueba van a salir los mismos temas que tú no diste porque quieres hacer otras cosas (Armando, docente de Cartagena, comunicación personal, julio de 2017).

Consideramos que la acción en el borde tiene las siguientes características:

\section{Ejercicios de enunciación}

El maestro que actúa en el borde ha reconocido que -en el marco del proyecto Educación Intercultural - trabaja con estudiantes indígenas, negros, afrodescendientes y palenqueros. En las instituciones de 
estos maestros y maestras, gran parte del currículo institucionalizado se asienta en conocimientos "científicos" que se presumen universales. Esa presunción ha llevado a que el resto de docentes asuman que pueden desarrollar su práctica pedagógica en cualquier contexto, sin modificar radicalmente sus contenidos. Así, universalizado el contenido, se universaliza también al estudiante.

El PIA, por el contrario, problematiza el contexto y esa problematización deviene en contenidos y metodologías. Ese ejercicio de problematización implica preguntarse por dos sujetos en ese contexto: estudiante y docente. En el marco de nuestro proyecto provocamos la reflexión sobre las diferencias étnico-raciales y de género en la escuela, lo que supone situar al estudiante $-\mathrm{y}$ al docente- en las múltiples posiciones que ocupa en la estructura social. Se trataba entonces de producir contenidos y metodologías situadas o conocimientos situados en palabras de Haraway (1991); pero, sobre todo, volver a la experiencia de la subalternidad un lugar de producción de contenidos en el aula. Dicha tarea implicó preguntarse: ¿quiénes son mis estudiantes? —en clave de raza, étnia, género, clase social, lo rural, lo urbano-, ¿de dónde vienen?, ¿qué desigualdades, violencias y discriminaciones enfrentan?, ¿qué efectos han producido esas experiencias en sus subjetividades? De esta forma, promovimos las siguientes reflexiones: ¿es pertinente el conocimiento que circula en el aula?, ¿ese conocimiento reafirma al estudiante o produce negación, autodesprecio y reproduce las desigualdades sociales?

Los interrogantes anteriores permitieron reflexionar sobre el lugar de producción del conocimiento que legítimamente circula en el aula; de esta manera, se pone al descubierto el sujeto particular de ese conocimiento que se arroga universal: hombres, blancos, europeos. Al tiempo, se pone en evidencia que los conocimientos producidos desde experiencias subalternas no registran en la escuela. En ese sentido, el diseño de los PIA supone contenidos y metodologías que se dejan afectar por los y las estudiantes: sus identidades, así como las desigualdades y 
violencias que enfrentan, para hacerles resistencia. De manera particular, el sufrimiento de un estudiante se vuelve contenido para enfrentar el sistema que le hace sufrir. Esto ocurrió particularmente con los casos de autodesprecio de niños y niñas negras que han experimentado el racismo. En ese mismo caso, docentes reflexionaron sobre el racismo presente en la episteme del currículo dominante eurocéntrico, en los textos escolares y en sus propias prácticas docentes.

Tenemos entonces que los lugares de enunciación de los y las estudiantes orientan la producción y elección de contenidos, muchos de los cuales actúan de manera emergente. Recuerdo de manera especial la experiencia del grupo de docentes de la Institución Educativa Liceo Bolívar, en Cartagena, que transformaron la forma de enseñar el tema de "Mi ciudad". Estas maestras siempre hacían referencia a Cartagena, y específicamente a lugares icónicos para el turismo que pocos de sus estudiantes visitaban. A partir de su PIA desarrollo una unidad temática titulada “¿De dónde vengo yo?” y descubrieron múltiples lugares de procedencia de sus estudiantes y sus familias, muchos de ellos rurales. En ese sentido, si bien Cartagena era la ciudad de los y las estudiantes en el momento actual, las maestras empezaron a incorporar esos otros lugares que hacían parte de la historia de vida de niños y niñas, y que no registran en el aula. Además, empezaron a rastrear literaturas y prácticas de estos lugares. Como aprendizaje anotaban además que, desde la pregunta ¿de dónde vengo yo?, los y las estudiantes adquieren un lugar relevante en los contenidos que se enseñan y que cada año este varía de acuerdo con los niños y niñas presentes en el aula. Antes, la unidad "Mi ciudad" se enseñaba sin modificaciones.

Ahora bien, se actúa desde un borde en tanto que en los currículos institucionalizados la experiencia del estudiante y las posiciones ocupadas en la estructura social no tienen la capacidad de alterarlo. Si bien, con esta actuación curricular fronteriza se mantiene ese lugar inalterable del saber oficial, hallamos que en esos bordes tienen lugar las afectaciones e interpelaciones que estudiantes y docentes han producido. 


\section{Lecturas del territorio y territorialización de la escuela}

Bajo la pretensión de universalidad del conocimiento que circula legítimamente en la escuela, en contextos urbanos como el cartagenero, varias de las instituciones educativas trabajadas se han entendido desde un lugar no-territorial favorecedor de la separación entre escuela y comunidad. En el ejercicio de caracterización inicial de estas instituciones, encontramos que ninguna sostenía vínculos sólidos con la comunidad y que, generalmente, la acción del docente ocurría en tiempos y espacios determinados que no excedían los límites geográficos y sociales de la escuela en sí misma. El diseño de PIA supuso preguntarse por el contexto en el que la escuela actúa, además de: ¿qué vínculos han construido estudiantes, familias y vecinos con ese territorio?, ¿qué disputas económicas, sociales y políticas actúan sobre él?, ¿qué actos de resistencia se generan desde las comunidades?, ¿cuál es el lugar de la escuela en este entramado de relaciones que implican vínculos, conflictos y resistencias? Todas estas preguntas eran parte de situar al estudiante: ¿quién es mi estudiante?

A menudo, la problematización arrojó que los y las estudiantes habitan territorios enfrentados al racismo, la segregación racial, el despojo, el extractivismo, la reducción, las afectaciones socioambientales, las afectaciones sobre la base material en la que se construye la espiritualidad de los grupos étnicos, entre otras. Todo lo anterior a causa del modelo de desarrollo imperante. Este ejercicio de problematización puso en evidencia el silencio del currículo frente a estas problemáticas, lo que restringe las posibilidades de articular resistencias desde la escuela. A través de los PIA, esas discusiones entran a las aulas, pero desde los bordes, no incorporadas al currículo oficial.

De esta forma, las maestras y los maestros que actúan en estos márgenes lo hacen a partir de la comprensión de que el currículo, como lo anota Castillo (2016), es un acto de poder. En ese sentido, encontramos que en la episteme del currículo dominante subyacen ideas lineales de 
progreso, desarrollistas e instrumentalistas. Así, por ejemplo, cuando en este currículo aparece el agua, casi nunca se acompaña de los significados construidos por los grupos étnicos alrededor de ella, el agua es entendida como recurso y no en su sacralidad, como lo es para los wiwas. Así lo manifiesta Yanis:

Trabajamos también muy específico el agua, les explicaba yo, les contaba yo una pequeña historia tradicional de nosotros, lo que significa el agua, de por qué no debemos jugar mucho en el arroyo, y por qué tampoco debemos jugar con los animalitos que hay en el arroyo. Porque muchas veces pasa que de pronto los niños se van a bañar y les gusta estar tirándose, jugando, tirando piedras y no es de pronto, no es bueno porque el agua es viva así como nosotros, y ella es una mujer. De pronto llega el día en que ella se puede cansar de que de pronto jugando con ella y de pronto ella se los puede llevar, puede suceder un caso que uno, son historias propias que yo se la contaba a los niños sencilla, porque de pronto ella está en lo profundo, pero algo que ellos pudieran entender, entonces ellos me decían que muchas veces los papás les decían que no estuvieran jugando en el arroyo, pero ellos no sabían por qué, simplemente les decían así (Yanis, docente wiwa, comunicación personal, junio 13 de 2017).

En el currículo oficial, el abordaje del agua -así como el de la tierra- no se acompaña de una discusión política que permita a los y las estudiantes comprender las disputas alrededor de ella y el lugar que en estas disputas ocupan los grupos étnicos.

\section{Acudir a sujetos, saberes y producciones subalternas. De lo inexistente a lo existente}

En conformidad con lo anterior, atender los lugares de enunciación de los y las estudiantes, así como sus problemáticas territoriales, convertidas en contenidos, supone para maestros y maestras acudir a otros referentes - sujetos, narrativas, historias - que han sido desestimados y negados en su potencial epistémico por ser considerados demasiado 
locales o por estar contaminados de subjetividad. Por tal razón, no están autorizados para hablar en la escuela desde ese lugar de conocimiento.

Hay una primera experiencia de incertidumbre en maestros y maestras al descubrirse ignorantes. El maestro enseña lo que sabe y el PIA lo situó en un lugar de no-saber y lo enfrentó a lo que consideraban inexistente. El ejercicio realizado se traduce en lo que Boaventura De Sousa llama sociología de las ausencias:

Lo que no existe es, de hecho, activamente producido como no-existente, o sea, como una alternativa no creíble a lo que existe. Su objeto empírico es imposible desde el punto de vista de las ciencias sociales convencionales. Se trata de transformar objetos imposibles en objetos posibles, objetos ausentes en objetos presentes. La no-existencia es producida siempre que una cierta entidad es descalificada y considerada invisible, no inteligible o desechable (2011, p.30).

Hubo entonces que rastrear esas ausencias para volverlas presencias en el aula, aunque, como hemos insistido, actuando en las fronteras del saber oficial. Fue así como se produjo una aproximación a sujetos ausentes en las escuelas como las escritoras y escritores racializados de regiones subalternizadas epistémicamente como el Caribe y el Pacífico: Mary Grueso, Shirly Campbell, Ana María Machado, Jorge Artel, Manuel Zapata Olivella, Ereidis Cásseres Navarro, Yesenia Escobar Espitia, Aminta Peláez; o a personajes literarios como la princesa africana Malaika, Kirikú, Mama Avo.

Lo anterior tiene importantes efectos epistémicos porque en esos bordes se libran disputas por el significado. En principio, cuando estas ausencias entran en la escuela, actuando desde los márgenes, los docentes reconocen lo que plantea Elizabeth Castillo (2016): “el racismo hace parte de la historia de la escuela, y la escuela hace parte de la historia del racismo". Como estrategia de contra-intervención, en los bordes 
ingresan ausencias que cuestionan el sistema racista. Encontramos que las producciones de estos sujetos desafían algunos principios de la episteme dominante, de manera particular, las representaciones que produce sobre los otros: una de las interpretaciones que se pone en el aula está relacionada con la existencia de África y los pueblos africanos antes de la colonización. En las instituciones educativas denominadas mayoritarias - sin enfoque étnico- y en las que no se desarrolla la cátedra de Estudios afrocolombianos, se muestra a las personas afrodescendientes como esclavas, ni siquiera esclavizadas. Se las explica desde los parámetros de la producción colonial de lo negro.

María Isabel Mena, a partir de un estudio de textos escolares utilizados para la enseñanza de la historia, señala que

[...] las Ciencias Sociales y Humanas continúan plagadas de relatos eurocéntricos y eurocentrados que sostienen por esa vía los principales estereotipos urdidos sobre los afrocolombianos desde la época colonial, por un lado, que su historia se inicia con la esclavización, por otro, que a pesar de esa circunstancia, viven alegres, danzando y ocupados de las tareas fuertes para las cuales están biológicamente equipados, y en tercer lugar estos imaginarios naturalizan, desde el punto de vista cultural, las relaciones construidas desde el mundo colonial (Mena, 2009, 106).

Las maestras palenqueras Mary Salgado y Esperanzada Obeso, vinculadas a nuestro proceso de formación, plantearon en la sistematización de su PIA que la enseñanza de la historia únicamente desde el lugar de la esclavitud, es decir, en clave colonial y no en perspectiva cimarrona, manifiesta un currículo diseñado para que estudiantes negros, afrodescendientes, palenqueros y raizales se autodesprecien y no se autorreconozcan.

En este contexto, personajes de cuentos como la princesa Malaika, Kiriku o la Niña Bonita posibilitan aproximarse a otras narrativas. El currículo oficial —que no ha sido aún lo suficientemente intervenido por 
los grupos étnicos - sigue reproduciendo la imagen estereotipada del negro. Por lo mismo, pedagógicamente, maestros y maestras empiezan a participar en luchas por la interpretación y la producción de sentido que rompan la relación significante de negro igual a esclavo, bruto, feo. Usar estas literaturas constituye una contra-estrategia de intervención para hacer que esos significados hegemónicos - estereotipantes y racistas - construidos alrededor de la población negra se agrieten y se dirijan hacia nuevas rutas que permitan el autorreconocimiento.

Otro principio cuestionado de la episteme dominante es aquel relacionado con que el cuerpo no es un lugar de producción de saberes. A partir de este interrogante, empiezan a aparecer sujetos y producciones, sobre todo literarias, donde el sujeto se enuncia, se expone a sí mismo como lugar reflexivo y reivindicativo. De manera particular, la reflexión del cuerpo como construcción social —racializada, generizada, sexualizada- y no como hecho meramente biológico entra al aula. El racismo es una experiencia corporal y en las instituciones educativas hemos encontrado que la experiencia de la negritud tiene un efecto nefasto en las niñas: el odio a su cuerpo (sus labios, nariz, pelo) por considerarlo feo, pues todas las representaciones corporales “adecuadas” están ligadas al imaginario de belleza blanca-europea, imagen reforzada por cuentos con larga presencia en la escuela.

Llamó la atención que, en clave literaria, maestras y maestros acudieron mucho a mujeres escritoras. Sucede que estas producían o producen su literatura a partir de la enunciación de sus propios cuerpos, ello resultó una estrategia potente para combatir el autodesprecio. Cuentos como Niña Bonita y poemas como Rotundamente Negra, de Shirly Campbell, donde el cuerpo de la mujer negra es enunciado y afirmado en su belleza, motivaron a maestras y maestros a utilizar estrategias de enunciación corporal para trabajar el racismo: mirarse en el espejo, dibujar autorretratos, hacer que niños y niñas acudieran a adjetivos positivos para describir cada parte de su cuerpo. Así, el cuerpo -lugar 
despreciado por la razón ilustrada - también emerge como contenido y metodología.

De manera particular, el PIA titulado "Peinados afro como señal de identidad y libertad", desarrollado por dos maestras palenqueras en Cartagena, implicó enseñar la historia afro haciendo peinados en las cabezas de los estudiantes, trenzando sus pelos. Como ellas mismas lo anotan, esto implicaba un contacto corporal docente-estudiante que siempre se ha procurado evitar en la institución educativa.

En principio, desde la perspectiva del currículo oficial, en su racionalidad monocultural, compañeros y compañeras, así como directivos, interpretaban que lo que sucedía en las aulas de estas maestras era un juego, un desorden, una pérdida de tiempo. Para estos, la relación establecida en el acto de peinar no era una relación de conocimiento. Peinar se interpretaba como una intervención feminizada asociada a la estética o al cuidado de otros, pero no como algo que ocurre en los espacios donde se desarrolla la razón, como el aula. Aun cuando estas maestras enseñaban la historia del pueblo afro en clave cimarrona a través de los peinados, estos contenidos y estrategias, agenciados desde los bordes, eran vistos como improductivos. Así, tributar al sistema de evaluación supone no solo legitimar ciertos contenidos, sino ciertas maneras de aprenderlos.

Igualmente -en esta misma lógica de las ausencias-, entraron al aula personajes comunitarios o figuras tradicionales (mamos, sagas, sabedoras, vecinos, vecinas) cuyas prácticas y experiencias vitales constituyeron fuentes legítimas de conocimiento, hablando de campos temáticos -que no evalúa la prueba Saber- despreciados por la escuela tradicional: peinados afro, el canto de las aves, la casa tradicional wiwa, las prácticas socioculturales y económicas de las comunidades afrourbanas alrededor del manglar, prácticas comunitarias de cuidado ambiental, entre otras. Así mismo, estudiantes y docentes salieron del aula y cuestionaron la idea de que la institución sea el único lugar donde el conocimiento válido se concentra y donde están las personas autorizadas para transmitirlo. Todo ello bajo la premisa de que todo lo que los y 
las estudiantes necesitan saber ya ha sido producido. Estas ausencias y metodologías desarrolladas en los bordes del saber oficial ponían de manifiesto el carácter incompleto de ese mismo saber.

Ahora, es necesario anotar que el ingreso fronterizo de estas ausencias también presenta sus particularidades. Notamos que dichas ausencias ingresan con mayor facilidad en ciertas áreas del conocimiento, como la literatura, la historia, la ética, incluso en las ciencias naturales o en algunos campos de esta, pero no lo hace en áreas como matemáticas o filosofía, pues su contenido, más que cualquier otro, se presume universal, de modo que la ausencia no puede afectarlo. Así, hay unos campos de conocimiento que se presumen como radicalmente inalterables y frente a los cuales maestros y maestras no han articulado curricularmente bordes posibles.

\section{Los currículos paralelos}

Aquí hacemos referencia a instituciones etnoeducativas que en sus modelos de educación mantienen el currículo oficial y, al mismo tiempo, desarrollan contenidos considerados conocimientos propios que tienen como fin preservar y reafirmar la cultura de los grupos étnicos. Tanto en este caso como en el anterior, no hay una alteración significativa de las políticas del conocimiento en las que se funda el currículo oficial. No alteran los sistemas de evaluación escolar, ni las lógicas disciplinares desde las que ha sido configurado el conocimiento que circula en las aulas (Rojas y Restrepo, 2012, p.157).

Para el caso del pueblo wiwa, encontramos que el modelo educativo Shama Zhigui define ejes de fortalecimiento cultural, áreas y asignaturas. Como ejes se tienen: educación intercultural, educación bilingüe, educación ambiental y educación en derechos. Llama la atención que la educación intercultural la definen como un "enfoque cultural alrededor de una educación propia acorde con la cosmovisión del pueblo wiwa y la asimilación de otros elementos culturales de otras sociedades en forma consciente y crítica” (OWYBT/MEN, 2012, p.52). 
Las áreas que se trabajan continúan siendo las mismas del currículo oficial (Ciencias Sociales, Ciencias Naturales, Humanidades, Matemática, Tecnología e Informática) y a estas se incorporan campos de conocimiento propio.

Los conocimientos propios están fijados en un campo de formación cultural del sujeto étnico sin potencial epistémico, sin adquirir estatus de conocimiento con aspiración nacional/universal. Son saberes para la formación/preservación del otro que no representan peligro de alteración para la episteme dominante en el sistema educativo colombiano. Estos conocimientos propios se mueven entre la visibilidad y la invisibilidad, entre la ausencia y la presencia. Son visibles y presentes en contextos locales de formación de alteridad, pero invisibles y ausentes en la idea de un currículo nacional homogéneo.

Llama la atención que, para algunos docentes, el modo de legitimar la educación propia que se desarrolla en contextos étnicos periféricos es obteniendo "buenos resultados" en las pruebas Saber, lo que equivale a decir que se están formando con éxito a niños y niñas de estos grupos étnicos a partir de ese currículo nacional homogéneo. Más aún, esto equivaldría a decir que la educación propia no pone en peligro ese currículo y que, justo por esto, puede seguir existiendo, formando al sujeto de la nación al tiempo que forma al otro de la nación. Se demanda el derecho a la etnoeducación a partir de una diferencia que no representa amenaza para las desigualdades sociales, en este caso, epistémicas.

[...] los nivelamos con los de acá. Ya hacemos ejemplos: llave, aquí le llaman manguera, o tapón, no hay relación, no le dicen qué haría usted con la llave, qué haría usted con el tapón si llega a ver la manguera abierta. Y le hemos aplicado las preguntas que traía eso, y el niño sí responde como el palito. Entonces eso ha hecho una estrategia también para demostrarle al gobierno que también hay una educación de calidad acá adentro de las comunidades indígenas. Y nos da resultado porque antes estábamos en 3.2, ahora estamos en $4.7[\ldots]$ nos dan otro lenguaje, nos miden como cualquier institución (Miguel, docente wiwa, comunicación personal, junio de 2017). 
Historia

Ética y valores

EDUCACIÓN INTERCULTURAL Ciencias Sociales

Filosofía

Territorio y Geografía

Derecho propio

Legislación indígena

Medicina tradicional

EDUCACIÓN BILIGUE

Ciencias Naturales

Naturaleza

Química

Física

Castellano

Dumuna

EDUCACIÓN AMBIENTAL

Humanidades

Ikun

Koguian

Inglés

Matemática

Matemática

Geometría

EDUCACIÓN EN DERECHOS Tecnología e Informática

Informática

Agricultura propia

Conocimientos propios Música tradicional

Tejido y tecnología

Lo anterior puede entenderse a la luz de lo que Castillo (2008) llama integracionismo administrativo: 
Con este esquema se produce un nuevo tipo de integracionismo, ya que los resguardos deben invertir los recursos destinados a la educación siguiendo la relacionalidad de la Ley 715 consistente en implementar un modelo educativo nacional estandarizado, que condiciona el acceso a los recursos por parte de las entidades territoriales al cumplimiento de las metas que dicho modelo define (Pruebas Saber, planes de mejoramiento, indicadores de gestión, etc.). Es decir, promueve la autonomía en el marco del integracionismo administrativo (p.24).

Otro asunto que llama la atención de los currículos paralelos, como se anotaba en líneas iniciales, es que, justo en ese paralelo entre lo propio y lo occidental se forma el sujeto wiwa, constituyéndose -en el campo pedagógico - a partir de una relación de alteridad constitutiva entre una episteme dominante -que no es propia ni cultural y éticamente deseable- y una subalternizada —que es propia y éticamente deseable-.

La pregunta central del proyecto del ecosistema fue cómo, o sea, comparar el ecosistema de afuera y el nuestro. En qué sentido, para nosotros el ecosistema es todo, y todo lo que está en el territorio para nosotros es importante. Así lo mismo, para el blanco, para el hermano menor también tiene importancia, pero ellos lo miran de una manera diferente, en el sentido de que de pronto es algo como desarrollo, y nosotros no lo miramos como desarrollo sino como conservación. Desde allí nosotros hemos trabajado en ese sentido dándole a conocer a los estudiantes cómo lo entienden allá afuera y cómo es lo nuestro. Con eso no queremos decir que el conocimiento blanco no es viable para nosotros. Yo creo que, aquí trabajando la experiencia, dando ejemplo a los estudiantes, los estudiantes van a comprender por qué allá afuera lo miran de una manera y nosotros de otra forma (César, docente wiwa, comunicación personal, junio 12 de 2017).

Cuando estudiamos el tema del ecosistema desde lo occidental, es un pensamiento que se diferencia del pensamiento de nosotros y de pronto de muchas otras etnias o culturas que hay en el mundo, y de pronto cuando uno entra hace esas comparaciones (Yanis, docente wiwa, comunicación personal, junio 13 de 2017). 
O sea, primeramente, comenzaron los hermanitos menores [no indígenas] y como el hermanito mayor se dio cuenta que construía y se caía [la casa] y construía y se caía, entonces comenzaron los hermanitos mayores [indígenas]. Entonces a ver si la de nosotros también se va a caer, a construir Urraga [casa tradicional wiwa]. Dice: "Comenzaron a traer los materiales como barro, horcón, lata, bejuco, pero no todo lo traían en el mismo tiempo, sino que pasaban días para traer un material. Para los hermanitos menores, el material que el hermanito mayor estaba apilando para construir Urraga, no era duradero ni fuerte. Que cuando el terremoto pasara, menos aguantaría”. O sea, para el hermanito mayor, de acuerdo a los materiales y la construcción que estaban haciendo, si la de nosotros fue más fuerte, con materiales más duraderos y ellos están construyendo con esos materiales, eso menos va a aguantar. Decían, se suponían ellos, menos aguantarían. "Después comenzaron a construir y demoraron para terminar la construcción de Urraga” o sea, ellos no lo hicieron el mismo tiempo. O sea, por ejemplo, el hermanito menor, comenzaron y al poco rato lo estaban terminando ya la casa. Pero por ejemplo acá dice que el hermanito mayor no lo hizo así, demoraron para terminar la construcción de Urraga. Luego pasó el terremoto y no se cayeron las casas (Emiliano, docente wiwa, comunicación personal, 12 de junio de 2017).

Así, en estos paralelos se "gestiona un particular diagrama de mismidades y diferencias", para el que traza unos contornos bien definidos (Rojas, 2011, 102).

Ahora, la etnoeducación afrocolombiana en el contexto cartagenero opera bajo condiciones totalmente diferentes al contexto indígena y wayúu. En el 2013, la Secretaría Distrital de Cartagena expidió el Decreto 0670 que focaliza veinticinco instituciones como etnoeducativas, esto como parte de la política educativa distrital para el fortalecimiento y reafirmación de la identidad étnico-cultural. Este decreto fue impulsado por el movimiento social afrodescendiente, que en el año 2012 había logrado la Política Pública de: enfoque diferencial para población afrocolombiana, negra, palenquera y raizal y en la cual la etnoeducación es uno de los capítulos. El decreto establece que 
[...] de acuerdo con el estudio adelantado por el Comité Distrital de Etnoeducación creado mediante Resolución 663 de 2008, en el Distrito de Cartagena existen Instituciones Educativas que atienden mayoría de población que se autoreconoce [sic] como afrocolombiana, raizal y palenquera o que adelantan Proyectos Etnoeducativos, por lo cual es necesario identificarlas, para focalizar acciones orientadas a la construcción de modelos educativos pertinentes, en los cuales se tengan en cuenta los criterios de integralidad, interculturalidad, diversidad lingüística, participación comunitaria, flexibilidad y progresividad, de acuerdo a lo señalado en el artículo 55 de la Ley 115 de 1994 (Decreto No. 0670, 20 de mayo de 2013).

Indica el decreto que las instituciones focalizadas iniciarían un proceso de resignificación del PEI, el cual debe adoptarse mediante un proceso de participación de los diferentes estamentos integrantes de la comunidad educativa (Decreto, 0670 de 2013). La mayoría de las instituciones focalizadas (19) corresponden a zonas rurales de Cartagena, en territorios insulares y continentales; apenas seis (6) corresponden a la zona urbana. El decreto tomó como criterio de focalización las comunas que, según el censo de 2005, presentaron mayor autorreconocimiento como población negra, afrodescendiente, palenquera y raizal, al igual que aquellas instituciones que ya venían agenciando proyectos etnoeducativos. Sin embargo, conviene hacer evidentes los conflictos que supone esta focalización.

El criterio fundamentado en el dato estadístico obvió elementos cualitativos más profundos puesto que hoy la reflexión que plantean maestros y maestras es que tanto estudiantes, como docentes, familias y organizaciones sociales de esos territorios en particular no necesariamente se habían enunciado desde este lugar identitario. Por el contrario, manifiestan que diferentes actores de la comunidad educativa se niegan a autorreconocerse como negros, afrodescendientes, palenqueros y raizales. En consecuencia, tampoco se han construido planes de vida comunitarios como grupo étnico. Así, se supondría que el censo respondería más a un autorreconocimiento individual, que colectivo-territorial que 
permitiera afirmar que la comunidad demandó un proyecto educativo conforme a sus aspiraciones como grupo étnico. Más o menos, los mismos maestros sienten que esta focalización responde a un ejercicio violento por parte de la Secretaría de Educación.

En este contexto, ¿qué cambios epistémicos podrían producirse y quiénes lo promoverían? Hay que considerar que estas instituciones venían de considerarse 'mayoritarias' para transitar, a partir del decreto, a etnoeducativas. Si bien se nombraron docentes etnoeducadores, el grueso de la planta docente no cambió. Se trata de maestros que, en su mayoría, no se habían preguntado por sus propias identidades étnico-raciales y que presumían, o presumen, que sus contenidos son aplicables a cualquier contexto, que no deberían ser 'etnizados'.

Al momento de realizar las caracterizaciones iniciales para dar inicio a nuestro proyecto, en las que involucramos a dos colegios etnoeducativos, maestros y maestras consideraban que las únicas diferencias que les exigían revisarse o replantearse metodológicamente -mas no en contenidoseran las relacionadas con dificultades de aprendizaje por discapacidades; atender estas dificultades suponía ser inclusivos. Las diferencias visibles se definían en función de las racionalidades propias de la escuela y aquello que posibilita/dificulta el aprendizaje en términos de la capacidad de aprender el conocimiento institucionalizado, sin modificarlo, es decir, hacer que el estudiante aprenda eso que debe ser aprendido.

La focalización supondría una escuela cuyo currículo se deja interpelar por las diferencias étnico-raciales; sin embargo, esto no era considerado como una diferencia con capacidad de interpelación curricular. Lo que ocurrió es que maestros y maestras continuaron con sus mismos contenidos y situaron la etnoeducación en campos y sujetos específicos. En términos del campo, sucedió que la etnoeducación se estableció como asignatura del área de las Ciencias Sociales. Para insistir, no solo no se han producido cambios curriculares o la llamada resignificación de PEI, sino que al currículo oficial solo se le agregó una asignatura llamada 
etnoeducación. Esto también se encuentra relacionado con el hecho de que en lo afrourbano no operan tan claramente las nociones de "conocimiento propio” como sucede en los pueblos indígenas.

Ahora bien, los maestros a cargo del área de ciencias sociales, en la que se inscribió la etnoeducación -sugiriendo que ésta solo tenía que ver con la enseñanza de la historia, pero no con las denominadas ciencias duras-, mantenían representaciones estereotipadas y floclorizantes de la población negra, afrodescendiente, palenquera y raizal, las cuales fueron trabajadas en el marco de este proyecto.

Es una materia, la doy yo, como hace tres años. Tres horas de sociales y una de etnoeducación [...] El Proyecto de Etnoeducación, para el 20 (de mayo) hay un trabajo que queremos elaborar un trabajo de las comidas gastronómicas de los etnos, de la raza étnica. También pienso hacer una obra de teatro, la harán de África, en sexto grado me toca América, Colombia, lo que es Palenque [...] En la presentación gastronómica se muestran las comidas y se evalúan [...] Al principio me dio duro, primero que todo porque como no soy de aquí, en mi tierra nunca se ha vinculado la esclavitud ni nada de eso, me sentía como rara, yo soy cachaca, a mí me dicen cachaca, yo digo que me discriminan, pero ya después me fui acostumbrando. Entonces al principio fue duro, pero después ya me acostumbré, no le paré bolas a nada, es más, yo la daba, pero con recelo porque sea como sea me iba a meter en algo no conocido, que no era mi área (Marta, docente de Cartagena, comunicación personal, marzo de 2016).

En otros casos, la asignatura llamada etnoeducación está a cargo de los etnoeducadores, mientras que el resto de las y los docentes no se sienten interpelados.

Desde el año pasado estamos tratando de renovar el PEI, porque el PEI de la institución no estaba adecuado, como estaba focalizada la institución etnoeducativa, se está trabajando en eso, incluir la parte etnoeducativa al PEI. En esa parte entramos los docentes. Por ejemplo, yo desde mi parte de Ciencias 
Naturales, mi proyecto consistió en lo que es la medicina tradicional. El año pasado hicimos una feria cultural, donde hablábamos de medicinas naturales, de cómo la utilizaban nuestros ancestros afrodescendientes, anteriormente no usaban químicos sino las plantas, medicinas curativas. Entonces, tenía imágenes de plantas, se les decía: "El orégano, se utilizaba para tal cosa y lo utilizaban de esta manera, lo tomaban, en diferentes presentaciones, hacían ungüentos". En esa semana cultural, como era mi proyecto, yo me responsabilicé de esa parte. Los docentes etnoeducadores diseñan un proyecto y no se deja de ejecutar, la idea es que todo el tiempo el componente esté ahí, dentro de las clases que yo dé no sólo debo impartirles: ¡La célula es esto!, sino buscarle la parte etnoeducativa para que ellos tengan conocimiento, en todo, toda mi clase debe girar en torno a la etnoeducación. La idea es que todos tengamos ese compromiso, pero hay docentes como que no les gusta, no les mueve mucho el cuento, como que "yo no participé, yo no soy de ese concurso, no tengo por qué meterme en eso" (Dani, docente etnoeducadora de Cartagena, comunicación personal, marzo de 2016).

Sin embargo, muchos etnoeducadores abandonan el proyecto con el que ganaron su plaza, incorporándose a los currículos oficiales, por considerar que dichos proyectos — que apelan al conocimiento ancestral- no tienen vigencia en la vida de los y las estudiantes. La idea de atraso es una forma de producir la no-existencia, pues declara atrasado todo lo que, según la norma temporal, es asimétrico en relación con lo que es declarado avanzado (De Sousa, 2011, p.31). Igualmente, lo étnico se interpreta más como un tema - o contenido específico- que como episteme. Como contenido específico, los etnoeducadores manifiestan que tampoco saben cómo abordarlo. En ese sentido, ha ocurrido que las plazas etnoeducativas han sido ocupadas por personas negras, afrodescendientes o palenqueras que no necesariamente son etnoeducadoras. La experiencia de un docente de una de las instituciones focalizadas como etnoeducativas nos ilustra al respecto:

Mi proyecto está basado en la matemática, la idea es que siempre hemos trabajado con métodos ancestrales, los jóvenes no conocen la yarda, la vara, la 
fanegada, todo ese tipo de medidas y de peso, la roba, hay ciertas medidas de peso que actualmente nosotros solo trabajamos con el gramo y el kilogramo, y la libra, siempre ha sido el kilo, ciertas medidas de peso no se conocen. Aquí, más que todo, en varias unidades se enseña eso, porque hay que complementarles a los niños lo que es un centímetro cúbico, qué valores tiene, entonces tratamos en ese aspecto también de combinarlo. Ese conocimiento está débil porque los pelaos no van a comprender bien y lo que hace uno es enredarlos en su futuro. Está la tecnología, es bueno que sepan que nuestros ancestros trabajaron con otras medidas, pero para que ellos la retomen como medida actual no tiene aplicabilidad. El que conoce sabe que sí existe, pero viabilidad para implementarlo a futuro no se puede, cómo yo le aplico que me haga esta medida aquí. Nosotros cada vez que podemos, en cualquier tema, por lo menos en mi caso, tratamos de ponerle algo de lo etnoeducativo. Hay temas que desafortunadamente no tenemos cómo ponerle el ingrediente de la etnoeducación, a pesar de que este colegio es etnoeducativo, hay temas que no le conseguimos. Hoy estoy dando naturales y me tocó darles exactamente lo que tenía que dar, ahí no aplicaba, pero sí siempre estamos, tenemos un área específica de etnoeducación, es una materia. No es tan sencillo, yo tengo el seminario de etnoeducación, por eso quiero hacer el diplomado, porque es muy corto, el contenido que uno a veces necesita para llevar nuestras materias se me hace difícil, de pronto en mi materia específica que es matemática es muy poco para dirigirlo que vaya todo a etnoeducación, no tengo la suficiente formación en ese aspecto, me gusta, pero no tengo la suficiente formación. Ahora en matemática muy poco incluyo contenidos étnicos, sobre todo esas medidas, pero son poquitos los temas. Lo hice en las medidas de peso y en las medidas, porque entre otras cosas nosotros aquí estamos usando centímetros cúbicos, estamos usando el peso el kilogramo, y no sabemos que hay una medida que se llama roba, que una roba tiene tantos kilos, que hay un peso que se llama el quintal, la vara, ciertas cosas, pero cuando uno pasa a otro tema, ya no tengo más nada, como si hubiese muerto lo que quería dar. En naturales muy poco lo utilizo, porque el contenido que yo sé de etnoeducación es poco, mi formación en etnoeducación fue a dos seminarios cortos que fui, no intensos (Wil, docente etnoeducador de Cartagena, comunicación personal, marzo de 2016). 
Además de convertir la etnoeducación en asignatura, algunas instituciones focalizadas han entendido esta perspectiva a partir de eventos de celebración multicultural de la diferencia como la semana de la afrocolombianidad, que se volvió obligatoria para estas instituciones y opcional para las mayoritarias. Aún en estos espacios, permanecen las representaciones estereotipantes. En el marco del proceso de formación, algunas maestras de instituciones etnoeducativas narraban que niños y niñas palenqueros, especialmente, eran llamados a realizar representaciones de la esclavitud. Siempre eran los cuerpos negros los marcados, expuestos e interpelados, bajo la premisa de que se están auto-representando, pero no había una discusión más profunda de la colonización y la colonialidad en la escuela.

De conformidad con lo anterior, la etnoeducación se presenta como un campo de tensiones en contextos afrourbanos. Entender eso supone preguntarnos: ¿qué lugares ocupan los sujetos racializados y las identidades étnico-políticas en un espacio como la ciudad?, ¿cómo se construyen las nociones de territorio?

\section{Para seguir (nos) cuestionando}

A partir de lo anterior, es posible pensar que la etnoeducación y la educación propia - son políticas educativas - son otro modo de celebrar la diferencia en el marco del Estado multicultural. Esta celebración permite que la diferencia exista, la ubica, la administra, la legisla, pero sin la capacidad de amenazar las desigualdades sociales.

Entendemos que lo epistémico es un campo de desigualdad social sobre el cual operan también injusticias y concentraciones de capital cultural que requieren ser redistribuidos. No redistribución en términos de acceso, es decir, no apelo aquí - o no solamente- a que los grupos étnicos accedan al "conocimiento". Me refiero a una redistribución que debe operar en el reparto desigual frente a lo que hoy tiene el estatus de conocimiento legítimo para ser enseñado en todas las aulas escolares 
del país. Cuestionamos entonces el hecho mismo de que la etnoeducación y la educación propia se asuman como meras políticas de reconocimiento de la diferencia, en el marco de las cuales celebramos orgullosamente que poseemos saberes propios o ancestrales, pero que, epistémicamente, se mantienen en un lugar no solo de alteridad, sino de subalternidad frente al sistema educativo colombiano. La redistribución supondría reconocer que existen diferentes conocimientos.

Boaventura de Sousa plantea que, en términos epistemológicos,

[...] la moderna sociedad capitalista se caracteriza por el hecho de que favorece prácticas en las que predomina el conocimiento científico [...] La injusticia social se basa en la injusticia cognitiva. Sin embargo, la lucha por la justicia cognitiva no tendrá éxito si se sustenta únicamente en la idea de una distribución más equilibrada del conocimiento científico. Aparte del hecho de que esta forma de distribución es imposible en las condiciones del capitalismo global, este conocimiento tiene límites intrínsecos en relación con los tipos de intervención en el mundo real que se pueden alcanzar. Estos límites son el resultado de la ignorancia científica y de una incapacidad para reconocer formas alternativas de conocimiento e interconectar con ellas en términos de igualdad (2011, p.36).

Monopolizado lo que se define como conocimiento dentro del currículo oficial, también se monopoliza una interpretación de la vida, de la relación de los humanos con la naturaleza, del ecosistema y sus elementos, una interpretación del desarrollo, de la historia, de cómo el conocimiento es construido/producido, del modelo de sujeto exitoso, de aquello que nos debe producir o no dilemas éticos, entre otros asuntos que nos habilitan para vivir socialmente.

Si bien algunos maestros y maestras vinculadas al proyecto articulan resistencias desde los bordes, desde lugares fronterizos con ese currículo oficial, también encontramos la posición en las instituciones educativas - sobre todo aquellas llamadas mayoritarias - de "permitirle" al docente que enseñe otros contenidos - definidos como prescindibles 
e improductivos, como señalamos antes - siempre que se enseñen, de manera prioritaria e inaplazable, los contenidos considerados oficialesevaluables-productivos. Así, el ejercicio docente desde otros lugares supone siempre un doble esfuerzo.

Estamos en deuda frente a la puesta en marcha de acciones y tránsitos necesarios para repolitizar la etnoeducación, la educación propia y las apuestas de educación intercultural que hoy operan en medio de la cooptación institucional. De igual forma, habría que pensar que, al tiempo que es preciso una redistribución epistémica en el seno mismo del sistema educativo colombiano y sus políticas de conocimiento, también esos contenidos y metodologías manifiestas en los bordes del currículo dominante son conocimientos que los estudiantes probablemente pongan en circulación en espacios no escolares: barrios, comunidades, colectivos y organizaciones sociales, cabildos, consejos comunitarios, en tanto que aquello presente en el borde tiene el potencial de formar sujetos políticos. En ese orden de ideas, si bien tenemos que hacer implosionar el sistema de educación, sabemos que no es el único objetivo de nuestra acción política porque, al interpelar a un sujeto escolarizado - estudiante-, sabemos también que este ocupa múltiples posiciones que exceden la escuela.

\section{Referencias}

Alcaldía Mayor de Cartagena de Indias (20 de mayo de 2013). Por la cual se determinan las Instituciones Educativas del Distrito de Cartagena donde se focalizan acciones orientadas a la construcción de Modelos educativos pertinentes [Decreto 0670 de 2013].

Castillo, Elizabeth (2008). Etnoeducación y políticas educativas en Colombia: la fragmentación de los derechos. Revista Educación y Pedagogía, XX(52), $15-28$.

Castillo, Elizabeth (2016). Módulo Currículo y Poder, Diplomado en Educación Intercultural. Proyecto Educación Intercultural por la Defensa de los Derechos de los Grupos Étnicos. Centro de Investigación y Educación Popular/ Programa Por la Paz (Cinep/PPP). Relatoría. 
Castillo, Elizabeth y Caicedo, José (2010). Las luchas por otras educaciones en el bicentenario: de la iglesia-docente a las educaciones étnicas. Revista Nómadas, (33), 109-127.

Castillo, Elizabeth y Caicedo, José (2016). Interculturalidad y justicia cognitiva en la universidad colombiana. Revista Nómadas, (44), 147-165.

Castillo, Elizabeth y Rojas, Axel (2005). Educar a los otros. Estado, políticas educativas y diferencia cultural en Colombia. Cali: Editorial Universidad del Cauca.

De Sousa, Boaventura (2011). Epistemologías del Sur. Revista Internacional de Filosofía Iberoamericana y Teoría Social, (54), 17-39. Consultada el 13 de julio de 2017.

Dietz, Gunther y Mateos, Laura (2011). Interculturalidad y educación intercultural en México. Un análisis de los discursos nacionales en su impacto en los modelos educativos mexicanos. México: Secretaría de Educación Pública, Coordinación General de Educación Intercultural y Bilingüe.

Hall, Stuart (1997). El trabajo de la representación. En S. Hall (Ed.). Representation: Cultural Representations and Signifying Practices (Traducido por Elías Sevilla Casas) (pp. 13-74). London: Sage Publications. Recuperado el 16 de octubre de 2013 de http://metamentaldoc.com/14_El_trabajo_de_la_ representacion_Stuart_Hall.pdf.

Haraway, Donna (1991). Ciencia, cyborgs y mujeres: la reinvención de la naturaleza. Madrid: Feminismos.

Mena, María Isabel (2009). La ilustración de las personas afrocolombianas en los textos escolares para la enseñanza de la historia. Historia del Caribe, 5(15), 105-122.

Ministerio de Educación Nacional (2010). Estándares básicos de competencias en lenguaje. Recuperado el 30 de septiembre de 2017 de http://paidagogos. co/pdf/estandares_lenguaje.pdf.

Organización Wiwa Yugumaiun Bunkuanarua Tairona (OWYBT) (2012). Shama Zhigui. Modelo Etno-Eductivo del Pueblo Wiwa. Valledupar: Ministerio de Educación Nacional. 
Restrepo, Eduardo y Rojas, Axel (2012). Políticas curriculares en tiempos de multiculturalismo: proyectos educativos de/para afrodescendientes en Colombia. Currículo sem Fronteiras, 12(1), 157-173.

Rojas, Axel (2011). Gobernar(se) en nombre de la cultura. Interculturalidad y educación para grupos étnicos en Colombia. Revista Colombiana de Antropología, 47(2), 173-198. 